\title{
ARGUMENTACIÓN JURÍDICA, LÓGICA Y DECISIÓN JUDICIAL
}

\section{Introducción}

1) Es conocido que, en la antigüedad, una de las razones del desarrollo de la lógica era la necesidad de controlar la validez de los diferentes argumentos y alegatos ante los tribunales. Sin embargo, los intentos de construir un discurso racional en el ámbito del derecho no se limitaron a las argumentaciones de los juristas, sino que también se extendieron al mismo discurso normativo, y, en este sentido, es habitual referirse a una lógica de normas o lógica deóntica. A pesar de estos vínculos, es frecuente encontrar opiniones escépticas acerca de la posibilidad y, eventualmente, de la utilidad de la aplicación de la lógica a la reconstrucción de problemas normativos ${ }^{1}$. Estas opiniones escépticas, algunas veces, proponen una noción de «lógica» alternativa a la lógica clásica y pretenden, como señala Raz: ${ }^{2}$

«...que el pensamiento o razonamiento jurídico están sujetos a una lógica jurídica especial. Esto algunas veces significaría que el razonamiento jurídico no está sujeto a leyes lógicas. Pero, de modo más frecuente, indica una creencia de que hay reglas adicionales de lógica que se aplican solamente al razonamiento jurídico».

2) $\mathrm{Si}$ se acepta que la lógica ofrece un criterio importante para evaluar la racionalidad de un discurso, entonces, es de gran importancia el análisis del papel que desempeña el razonamiento deductivo en el conocimiento y justificación del derecho. En este trabajo discutiremos

${ }^{1}$ Vernengo, Roberto, «Derecho y Lógica: un Balance Provisorio», en Anuario de Filosofía del Derecho, Madrid, 1987. También, «Racionalidad Jurídica y Lógicas Normativas», en Análisis Filosófico, vol. X, No 2, 1990 101.

${ }^{2}$ Raz, Joseph, «The Inner Logic of Law», en Rechistheorie, Beiheft 10, Berlín. 1986, pag. 
dos tesis relativas al papel de la lógica en la justificación de las decisiones jurídicas y, para acotar nuestro análisis, consideraremos solamente a las decisiones judiciales.

a) Tesis de la Inseparabilidad. Esta tesis sostiene que una teoría del razonamiento jurídico justificatorio tiene que admitir una conexión necesaria entre derecho y moral. A diferencia de las tesis clásicas del derecho natural, la vinculación entre ambos sistemas normativos no implica la adecuación moral del derecho positivo; sino que la premisa principal de un razonamiento jurídico justificatorio es una norma o principio moral y, por consiguiente, la justificación de las decisiones judiciales implica el uso de normas y principios morales. Entonces, la pretensión de justificar decisiones normativas con independencia de la moral constituye una falacia; un error lógico (y no meramente axiológico) y, por tanto, esta pretensión de independencia sería -lato sensu- una actitud irracional.

Esta tesis será analizada en la sección II.

b) Tesis de la Insuficiencia. Tradicionalmente, el modelo explicativo de las decisiones judiciales es una generalización del esquema deductivo válido modus ponens: una decisión judicial se justifica a partir de una norma, la descripción de los hechos de un caso y determinadas reglas de inferencia. En un sentido amplio, este modelo clásico pretende ser una reconstrucción adecuada de procesos argumentativos y decisorios de los órganos jurisdiccionales. Sin embargo, ha sido objeto de numerosas críticas; por ejemplo: distinción arbitraria entre la identificación de las normas y la identificación de los hechos, insuficiente atención a la justificación de los argumentos fácticos, racionalización (en lugar de descripción y explicación) de las decisiones normativas, etc. Pero, tal vez una de las críticas más importantes, es que el modelo clásico no se puede utilizar en los denominados «casos difíciles». Esto nos conduciría al siguiente dilema: por una parte, el modelo es inadecuado porque proporciona una explicación incompleta ya que no es aplicable a los casos difíciles; o bien, por otra parte, es inadecuado porque conlleva una tendencia reduccionista y no distingue entre casos fáciles y casos difíciles.

Apoyada en estas consideraciones, la tesis de la insuficiencia sostiene que la justificación de las decisiones judiciales no puede reconstruirse adecuadamente conforme al razonamiento deductivo y, por consiguiente, es necesario una teoría que explicite las condiciones de validez de los argumentos que no pueden ser controlados por la lógica deductiva.

Esta tesis será analizada en la sección III. 


\section{Decisión y Justificación}

1) Parece existir consenso en que la justificación de una decisión normativa exige el desarrollo de un razonamiento práctico. Esta exigencia conduce a complejos problemas respecto de la naturaleza de las normas y la relación de éstas con las razones para la acción. Una conocida clasificación de las razones en una inferencia práctica es la siguiente: ${ }^{3}$

a) razones completas: son el conjunto de premisas no superfluas de un razonamiento práctico válido;

b) razones operativas: son las premisas «prácticas», i. e. normas, constitutivas de razones completas;

c) razones auxiliares: son los juicios de hecho que indican medios para satisfacer razones operativas.

Generalmente, se admite que si la conclusión de una inferencia práctica es una norma, entonces, las razones operativas son necesariamente normas. Pero, ¿las normas jurídicas pueden ser razones operativas de una inferencia válida? Al respecto, Carlos Nino señala: ${ }^{4}$

«... [H] objetado, sin embargo, esta idea de que las normas jurídicas, entendidas como juicios deónticos, puedan ser razones autónomas para justificar decisiones. Los argumentos que expuse allí se pueden sintetizar de este modo: si los juicios en cuestión son aceptados como premisas del razonamiento práctico en virtud de su contenido, ellos son indistinguibles de juicios morales... En cambio, si los juicios son aceptados en virtud de su origen, como este origen es un hecho que en sí mismo no determina la aceptación de la norma, debe haber un principio normativo subyacente que hace relevante tal origen para aquella aceptación...»

Esta caracterización impone la siguiente conclusión: si la justificación de una decisión involucra razones morales, entonces, la exigencia de justificación jurídica de una decisión judicial -o, al menos, una justificación independiente de normas o principios morales- es imposible de satisfacer. Por consiguiente, toda justificación es justificación moral y toda obligación jurídica sería una especie de obligación moral ${ }^{5}$.

${ }^{3}$ Raz, Joseph, «Introducción», en Razonamiento Práctico, Raz, J.(ed), Fondo de Cultura, México, 1986, pág 15 y ss, pág 28, 29 y ss. Raz, Joseph, Practical Reason and Norms, 21 edición, Hulchinson, Londres, 1990, pág. 22 y ss; pág. 33, 34, 35. Nino, Carlos, La Validez del Derecho, Astrea, Buenos Aires, 1985, pág 131. De Páramo, Juan Ramón, «Razonamiento jurídico e interpretación constitucional» en Revista Española de Derecho Constitucional, $\mathrm{n}^{\circ} 22$, pág. 98. Bayón, Juan Carlos, La Normatividad del derecho. Deberes Jurídicos y Razones para la Acción, Centro de Estudios Constitucionales, Madrid, 1991, pág. 86 pág. 30

${ }^{4}$ Nino, Carlos, El Constructivismo ético, Centro de Estudios Constitucionales, Madrid, 1989,

${ }^{5}$ Nino, Carlos, El Constructivismo Ético, ob cit, pág. 115 
2) Conforme a estas afirmaciones, y a los efectos de mostrar la vinculación lógica entre normas (principios) morales y las decisiones de los jueces, es frecuente reconstruir el razonamiento judicial de acuerdo al esquema modus ponens. En este sentido, y siguiendo a Nino, Juan Ramón de Páramo expone el siguiente argumento justificatorio: ${ }^{6}$

Argumento $(A J)$ :

«1) Se debe obedecer a $X$, siempre que $X$ sea un legislador elegido mediante un procedimiento democrático.

2) El legislador $X$ ha sido elegido democráticamente.

3) X ha dictado una norma jurídica que dice «si p, entonces debe ser q».

4) Si p, entonces debe ser q.

5) $\mathrm{p}$

6) q.»

Es evidente que la conclusión 6) no se sigue de las premisas y tiene que ser sustituida por:

$\left.6^{\prime}\right)$ debe ser q.

Pero, conforme a las definiciones introducidas anteriormente, una razón completa es un conjunto de premisas no superfluas de un razonamiento práctico. Una premisa es superflua cuando no es necesaria ni suficiente para derivar la conclusión del argumento, i.e. 6'. En el esquema analizado, 6' se infiere de 4 y 5 , es decir: las premisas 4 y 5 son necesarias y conjuntamente suficientes para la derivación de 6'. Por tanto, las restantes premisas son superfluas en esta inferencia. Esto significa que la justificación normativa de 6' es la norma jurídica 4. La reticencia a admitir esta conclusión se fundamenta, al menos, en tres argumentos:

(i) Si la premisa mayor (razón operativa) es aceptada en virtud de su contenido, entonces, funciona en el razonamiento práctico como una norma moral.

Pero, el hecho de que las normas jurídicas funcionen de manera similar a las normas morales en el razonamiento de los sujetos no prueba que no existan diferencias entre ambos tipos de normas. De igual modo, el que las normas desempeñen el mismo papel que las decisiones en el razonamiento de los sujetos que las siguen ${ }^{7}$, no implica que no existan diferencias entre ambas. Si se admite que un enunciado funciona como norma moral porque la aceptación del mismo obedece a razones morales,

${ }^{6}$ De Páramo, Juan R., ob. cit., pág. 99 y 100.

${ }^{7}$ Raz, Joseph, «Las Razones de las Acciones, decisiones y Normas» en Razonamiento Práctico, ob. cit., pág. 262. 
cabe señalar que no por ello el enunciado se convierte en una norma moral. El carácter del enunciado no debe confundirse con el carácter de las razones en las que se apoya su aceptación

(ii) El segundo argumento puede presentarse del siguiente modo. Si se acepta que el fundamento de una decisión judicial sólo puede ser una norma jurídica entendida como un juicio normativo, entonces es necesario establecer que este juicio normativo justificatorio es, al fin y al cabo, una norma jurídica ${ }^{8}$.

Al respecto consideremos el siguiente comentario de Byrce: ${ }^{9}$

«En un municipio un ciudadano es requerido a pagar un impuesto de pavimentación. Pregunta por qué debe pagarlo y es remitido a la resolución del Ayuntamiento imponiéndolo. Entonces pregunta qué autoridad tiene el Ayuntamiento para establecer el impuesto y es remitido a los artículos de la ley del Parlamento de donde el Ayuntamiento deriva su competencia. Si él lleva más allá su curiosidad y pregunta qué derecho tiene el Parlamento para conferir esta competencia, el recaudador de impuestos sólo podrá contestar que todos saben que en Inglaterra el Parlamento hace el derecho y que, en derecho, ninguna otra autoridad puede anular o ni siquiera interferir ninguna expresión de la voluntad del Parlamento. El Parlamento es supremo por encima de todas las demás autoridades o, en otras palabra, el Parlamento es soberano».

Los argumentos de esta cita pueden ser expresados de modo similar a las premisas del razonamiento (AJ) expuesto por J. R. De Páramo (véase ut supra). El primer párrafo responde a una cuestión que puede representarse análogamente a las premisas 4), 5) y 6'):

4) $\mathrm{Si} \mathrm{z}$ es un residente en el ayuntamiento A entonces debe pagar el impuesto I.

5) $z$ es un residente en el Ayuntamiento A.

6) $\mathrm{z}$ debe pagar el impuesto I.

Desde el punto de vista de la lógica este es un argumento completo. En el caso que se acepte una lógica de normas, este es un claro supuesto de aplicación de modus ponens. Es posible, sin embargo, preguntarse si la obligación expresada por 6) es una obligación jurídica; entonces

${ }^{8}$ «Una vez que aceptamos que el fundamento de una proposición justificatoria particular en un típico razonamiento práctico jurídico sólo puede ser una norma jurídica entendida como un juicio normativo, es razonable plantearse la pregunta acerca de cómo sabemos que ese juicio normativo en el que el juez se basa para fundamentar su decisión es, al fin y al cabo, una norma jurídica». Nino, Carlos, «Sobre los derechos morales», en Doxa, no 7 , pág. 318.

${ }^{9}$ La cita la tomamos de Raz, Joseph, The Concept of Legal System, Clarendon Press, Oxford, 1980, Pg. 99. 
debemos mostrar que 4) es una norma jurídica. Para ello, como la cita de Bryce sugiere, no hace falta ningún razonamiento práctico, sino solamente un razonamiento teórico apoyado en las siguientes definiciones:

Una norma $\mathrm{N}$ es jurídica:

$\mathrm{Df}_{\mathrm{a}}$ : Si $\mathrm{N}$ es una norma soberana (las normas promulgadas por el Parlamento inglés en el caso de Bryce) entonces $\mathrm{N}$ es jurídica;

$\mathrm{Df}_{\mathrm{b}}$ : $\mathrm{Si}$ una norma jurídica $\mathrm{N}$ autoriza a un órgano $\mathrm{O}$ a dictar una norma $\mathrm{N}^{\prime}$ y $\mathrm{O}$ dicta $\mathrm{N}^{\prime}$, entonces $\mathrm{N}$ es una norma jurídica.

Ahora puede argumentarse así:

1) Existe una norma del parlamento inglés (soberana) que autoriza a los ayuntamientos a dictar normas sobre impuestos municipales.

2) El ayuntamiento A ha dictado la norma (contenida en 4) sobre impuestos.

3) La norma contenida en 4') es jurídica.

La norma a la que se refiere el enunciado 1) es jurídica en virtud de $\mathrm{DF}_{\mathrm{a}}$. La verdad del enunciado 2) depende de determinados hechos empíricos. La verdad de 3) no se deduce de las premisas 1) y 2) solamente, sino de estas premisas más la definición de norma jurídica ofrecida. Dado que según $\mathrm{DF}_{\mathrm{b}}$, una norma es jurídica si ha sido dictada por una autoridad competente, entonces la norma contenida en 4) es jurídica. Si se quiere puede presentarse cómo sería el argumento completo:

a) Si existe una norma del Parlamento inglés entonces esta norma es jurídica.

b) Existe una norma $\mathrm{N}$ del parlamento inglés que autoriza a los Ayuntamientos a dictar normas sobre impuestos municipales.

c) La norma $\mathrm{N}$ es jurídica.

d) Si una norma jurídica $\mathrm{N}$ autoriza a un Ayuntamiento a dictar normas sobre impuestos municipales y un Ayuntamiento dicta una norma N' sobre un impuesto municipal I, entonces N' es jurídica.

e) El Ayuntamiento A ha dictado la norma: 'Obligatorio pagar el impuesto municipal I'.

f) La norma 'Obligatorio pagar el impuesto municipal I' es jurídica.

Obviamente, es posible preguntarse: ¿por qué debo obedecer las normas jurídicas?, o en el caso del juez ¿por qué deben mis sentencias justificarse en normas jurídicas? Esta es una cuestión distinta y no puede contestarse más que apelando a alguna cuestión extrajurídica. Pero no puede sostenerse que el razonamiento justificatorio del juez deba, por razones lógicas, utilizar una premisa moral. Un razonamiento como el anterior es suficiente para que el juez justifique su decisión en el derecho. 
Es importante advertir que los enunciados descriptivos como 'Es obligatoria la conducta p', siempre hacen referencia a la existencia de algún código de normas. En realidad, son enunciados que presuponen un contexto normativo determinado. El contexto nos indica a qué código se refiere y de esta forma podemos saber el valor de verdad del enunciado. Es posible que un código A prescriba la conducta $\mathrm{p}$ y otro código $\mathrm{B}$ no la prescriba; entonces, en el contexto de A, el enunciado es verdadero y en el contexto de B es falso. En realidad, los sentidos de las proferencias del enunciado son distintos. En el primer caso, deberíamos decir: 'De acuerdo a A, la conducta $\mathrm{p}$ es obligatoria'; y en el segundo caso: 'De acuerdo a $\mathrm{B}$, la conducta $\mathrm{p}$ no es obligatoria'.

En este sentido, uno de los posibles razonamientos de un juez acaba cuando muestra que de acuerdo al derecho (un código de normas), está obligado a dictar la sentencia $\mathrm{S}$, y dicta S. Si S se deduce de una norma jurídica y de la descripción de los hechos relevantes, entonces S está justificada en el derecho.

Sin embargo, el juez puede preguntarse por qué debe obedecer las normas jurídicas. Esta pregunta ya no está referida a una cuestión de obligatoriedad jurídica, sino de obligatoriedad de acuerdo a algún otro tipo de código normativo. Algunos parecen creer que esta pregunta está referida siempre a la obligatoriedad moral ${ }^{10}$. También esto es dudoso; puede ser referida a la obligatoriedad religiosa (algunos códigos religiosos obligan a obedecer a las autoridades políticas) o a otros tipos de códigos normativos. En algún momento el juez tiene que usar alguna norma y tomar una decisión; y no sólo mencionar normas y hacerse preguntas por su obligatoriedad ${ }^{11}$.

Es cierto, sin embargo, que identificar una norma como jurídica presupone el uso de un criterio que sirva para tal identificación. H.L.A. Hart, como es sabido, sostiene que un sistema jurídico existe cuando los órganos de aplicación de un grupo social usan el mismo criterio para identificar las normas jurídicas de ese grupo. A ese criterio, Hart lo denomina regla de reconocimiento. Podemos preguntarnos ahora, ¿por qué un juez debe usar, para identificar el derecho, la regla de reconocimiento? Si la pregunta es de carácter conceptual, la respuesta es analítica: porque si no, no identificará una norma jurídica. Si la pregunta es de carácter normativo, ¿por qué debe identificar una norma jurídica?, la respuesta ya depende de otras consideraciones. Si presuponemos, como parece presuponer Ruiz Manero ${ }^{12}$,

${ }^{10}$ Nino, Carlos, El Constructivismo ético, ob cit, pág. 114 y 115.

${ }^{11}$ Bulygin, Eugenio, «Algunas consideraciones sobre los sistemas jurídicos», en Doxa, 9,1991, Pg 274.

${ }^{12}$ Ruiz Manero, Juan, Jurisdicción y Normas, Centro de Estudios Constitucionales, Madrid, 1990, pág. 174 y ss. 
que cualquier respuesta que se dé a esta pregunta debe terminar en una razón última, y también que analíticamente (esto es, por definición) las razones últimas son razones morales $^{13}$, entonces es cierto que la aceptación de la regla de reconocimiento presupone razones morales. Pero, ¿por qué debo dar razones últimas de mi aceptación de la regla de reconocimiento?, y ¿por qué debo aceptar como últimas las razones morales? ${ }^{14}$

Por otra parte, es imaginable (conceptualmente) una sociedad en donde todos los órganos de aplicación y todas las autoridades piensen que sus reglas jurídicas son inmorales, pero las impongan por razones inicuas (por conservar la dominación, por ejemplo) y en donde los ciudadanos acepten las normas por convicción (la dominación es perversamente eficaz) o por miedo (la dominación es eficazmente perversa). Decir que como esas razones son las últimas razones, entonces son razones morales parece un criterio muy poco intuitivo para identificar normas morales.

(iii) Sin embargo, los motivos para rechazar a las normas jurídicas como razones operativas podrían ser que: ${ }^{15}$

«... el defender la idea que sostiene la tesis de que caben tantas justificaciones como sistemas normativos existan, vacía tanto el contenido de la moral que hace que nuestro razonamiento práctico no sólo no sirva para dirimir conflictos prácticos, sino que no sirva para nada, que produce su desintegración por la perdida de su función.»

La tesis de la fragmentación del discurso práctico, según la cual existen tantas justificaciones como sistemas normativos haya, puede interpretarse al menos en dos sentidos diferentes. En primer lugar, puede entenderse normativamente, es decir, como una tesis que recomienda la existencia de múltiples perspectivas de justificación. Consecuentemente, la oposición a esta postura consistirá, también, en una tesis normativa: no debe fragmentarse el discurso práctico. Para este último punto de vista, la unidad del razonamiento práctico constituye una condición necesaria para que el mismo pueda cumplir con su función de resolución de conflictos prácticos. Sin embargo, esta afirmación presupone un concepto diferente de razonamiento práctico. El concepto considerado previamente no hace referencia a un procedimiento

${ }^{13}$ Nino, Carlos, La Validez del Derecho, ob cit, pág. 133.

${ }^{14}$ Bulygin, Eugenio, «Regla de Reconocimiento: norma de obligación o criterio conceptual. Respuesta a Ruiz Manero», en Doxa, No 19, pág. 315 y 316.

${ }^{15}$ De Páramo, Juan, «Razonamiento jurídico e interpretación constitucional», ob cit, pág. 100. 
para resolver conflictos, independientemente de su unidad o fraccionamiento. En cambio, el concepto de razonamiento que alude al cotejo o comparación de razones sí puede entenderse como un modo de resolución de conflictos prácticos. En este sentido, el razonamiento práctico es un método para elegir una, de entre dos o más razones en conflicto, i.e. la razón más adecuada, conveniente, etc. ${ }^{16}$

Esta precisión es indispensable para advertir que mientras hablemos de razonamiento práctico en sentido clásico, su función no queda en absoluto afectada por la existencia de una pluralidad de marcos normativos a partir de los cuales se puede ofrecer una justificación. Consecuentemente, deberá ser otra razón, diferente a la perdida de función, el fundamento de una tesis normativa contraria a la fragmentación del razonamiento práctico.

Una posición diferente y con presupuestos más fuertes, es la que sugiere una interpretación descriptiva de la tesis en cuestión, i.e. el razonamiento práctico es unitario y sostener su fragmentación es incurrir en error. Con mayor precisión puede decirse, según Nino $^{17}$, que este error consiste:

«en una profunda incomprensión acerca de las reglas formales a que está sometido nuestro razonamiento práctico en general... que incluye una regla de prioridad que impide su desintegración; esa regla es que los principios morales son el último tribunal de apelación para justificar una acción que cae bajo su dominio; es decir, que las razones de índole moral excluyen cualquier otro tipo de razones en las situaciones en las que son aplicables»».

Analizar esta interpretación requiere destacar, nuevamente, la existencia de un significado distinto de la noción «razonamiento práctico»y su función de «justificación». En un sentido estrictamente lógico, la justificación puede entenderse como una relación de deducción existente entre las premisas y la conclusión de un argumento, sea éste práctico o teórico. Como una extensión de este concepto, «justificar» puede entenderse como la acción de explicitar las premisas de las que un contenido (conclusión) se deduce. La justificación en sentido lógico es ajena a la corrección material del argumento. En otras palabras, así como en un razonamiento teórico la validez del mismo no supone la verdad de las premisas, en un razonamiento práctico, la validez del argumento no supone la corrección o bondad de aquellas. Pero, la interpretación que discutimos, fundamentada del modo

\footnotetext{
Doxa, $\mathrm{n}^{\mathrm{o}} 10$.

${ }^{16}$ Navarro, Pablo y Redondo, Cristina,. «Normas Jurídicas y Razonamiento Práctico», en

${ }^{17}$ Nino, Carlos, La Validez del Derecho, ob cit, pág. 64 y 65.
} 
mencionado anteriormente, supone que hay razones mejores que otras y sólo las mejores razones justifican. Esto es lo que comúnmente se distingue con expresiones como justificaciones prima facie y justificaciones concluyentes, admitiendo que sólo estas últimas constituyen una verdadera justificación. Para entender las implicaciones de esta tesis es útil destacar dos suposiciones sobre las que se asienta.

En primer lugar, supone un concepto más comprensivo y no descriptivo de justificación. Esta noción valorativa requiere no sólo la existencia de una relación lógica adecuada (justificación en sentido lógico) sino también la presencia de premisas calificadas, i.e. $\operatorname{correctas}^{18}$.

En segundo lugar, esta tesis supone la existencia de una respuesta única a la pregunta acerca de las razones adecuadas; esto es así porque para que haya unidad es imprescindible que no existan dos razones igualmente correctas (concluyentes) que justifiquen acciones diferentes. Esta posición tiene que negar, en última instancia, un pluralismo valorativo porque de lo contrario deja abierta la posibilidad de dos marcos justificatorios igualmente plausibles y con ello reaparece el fraccionamiento del razonamiento práctico que se pretende impugnar, aun cuando esto ocurra dentro del ámbito de la moral ideal.

En resumen, conforme a esta posición, el razonamiento práctico justificatorio no es solamente un razonamiento lógico, sino que requiere además la corrección material del mismo, i.e. la bondad de las premisas. Adicionalmente, es necesario que para cada situación de justificación sólo haya una que lo sea.

Es interesante señalar que una tesis de este tipo debe afrontar un problema particularmente grave a la hora de identificar cuál, de entre todas las alternativas, es la premisa correcta. Las diferentes respuestas ofrecidas a este problema epistémico y la inexistencia de un método infalible de búsqueda parecen demostrar que aun admitiendo los presupuestos de esta tesis estamos irremediablemente limitados a esbozar diferentes marcos normativos que, por ser considerados los más plausibles, se proponen como puntos de partida de la justificación. Esto significa que la fragmentación es inevitable, dadas nuestras limitaciones epistémicas ${ }^{19}$.

${ }^{18}$ Para una distinción entre ambos sentidos de justificación, véase: Jääskinen, Nilo, «External Justification of Propositions in Legal Science» en Man, Law and Modern Forms of Life, Bulygin E. et al (eds), Rediel, Dordrecht, 1985.

${ }^{19}$ Alchourrón, Carlos y Bulygin, Eugenio, «Verdad Deóntica y Valores» en Análisis Lógico y Derecho, Centro de Estudios Constitucionales, Madrid, 1991, pág. 602 y ss. 
En conclusión:

a) suponiendo el sentido lógico de justificación, es incuestionable que existen tantas justificaciones como premisas podamos encontrar en relación de deducción lógica con la conclusión;

b) suponiendo el sentido valorativo de justificación, también debemos admitir que hay tantas justificaciones como premisas lógica y moralmente adecuadas podamos señalar en relación con el contenido de la conclusión en cuestión;

c) suponiendo la tesis moral de la única respuesta correcta, aún tenemos que reconocer el fraccionamiento epistémico de nuestro razonamiento práctico.

Por último cabe destacar que dentro de una teoría positivista no ideológica del derecho, al hablar de normas jurídicas como premisas de justificación no se toma este concepto en sentido valorativo, i.e. no se pretende que las premisas sean moralmente adecuadas, y menos aún que sean las únicas moralmente adecuadas. Ello no es necesario para el sentido lógico de justificación utilizado por esta teoría. Para satisfacer esta noción es suficiente contar con un criterio que permita identificar las normas jurídicas y, a partir de allí, una vez determinada la norma aplicable y la descripción de los hechos subsumibles en ella, se puede inferir una conclusión que estará justificada en relación a estas premisas.

\section{Decisión y Argumentación Jurídica.}

1) La expresión «decisión judicial» es ambigua ${ }^{20}$. Por una parte, se refiere al acto de decidir y, por otra parte, al contenido de la decisión. El contenido de una decisión está jurídicamente justificado si y sólo si se deriva lógicamente de una norma jurídica $\mathrm{N}$ y la descripción de ciertos hechos. El acto de decidir está jurídicamente justificado si y sólo si está autorizado en un sistema jurídico $\mathrm{Sj}$.

Otra distinción bien conocida es la que se hace entre la justificación de la conclusión de una inferencia (I), y la justificación de las premisas de la inferencia.(I). Siguiendo una terminología ampliamente aceptada, denominaremos a ambos tipos de justificación «justificación interna» $\mathrm{y}$ «justificación externa» respectivamente.

Es frecuente reconstruir la justificación interna del contenido de una decisión conforme al argumento deductivo modus ponens. Esto plantea, al menos, dos importantes problemas, que serán discutidos en lo que resta de este trabajo:

${ }^{20}$ Caracciolo, Ricardo, «Justificación normativa y pertenencia» en Análisis Filosófico, VIII, $\mathrm{n}^{\mathrm{o}} 1,1988$, pág. 41 y ss. 
(i) la caracterización de la validez lógica de una inferencia normativa;

(ii) la justificación de la elección de las premisas de un argumento.

2) En cualquier inferencia, ya sea teórica o práctica, es necesario distinguir cuidadosamente entre la elección de un conjunto de premisas $\mathrm{P}$ y la derivación de la conclusión a partir del conjunto $\mathrm{P}$. La falta de una adecuada distinción entre estos aspectos de la justificación de una decisión puede provocar importantes confusiones. Es verdad que frecuentemente surgen dificultades relativas a la selección de las premisas de un argumento; pero esto no tiene ninguna incidencia en la validez de una inferencia: antes de la elección de las premisas, no es posible establecer ninguna inferencia y después de establecer las premisas sólo resta analizar la validez lógica de la inferencia. Las dificultades, epistemológicas y psicológicas, relativas a la elección de las premisas no afectan en manera alguna al razonamiento deductivo en general y a la validez del esquema inferencial modus ponens en particular ${ }^{21}$.

Una diferencia importante entre justificación interna y externa es la siguiente: la elección de las premisas de una inferencia (I) es el resultado de un proceso de deliberación y argumentación que se desarrolla conforme a criterios diferentes a los proporcionados por la lógica deductiva. Por el contrario, la justificación de la conclusión de una inferencia (I) depende de la validez lógica de (I).

Al respecto, en una valiosa contribución al estudio de la argumentación jurídica, Atienza señala:22

«... justificar una decisión en un caso difícil, significa algo más que efectuar una operación deductiva consistente en extraer una conclusión a partir de premisas normativas y fácticas.»)

O, también: ${ }^{23}$

«La justificación interna es tan sólo cuestión de lógica deductiva, pero en la justificación externa hay que ir más allá de la lógica en sentido estricto».

Un caso puede ser un «caso difícil», al menos, por: ${ }^{24}$

a) Problemas normativos: existen dudas sobre de qué manera hay que entender los términos de una determinada formulación normativa; 92-93, 94, 96 .

${ }^{21}$ De Páramo, Juan, «Razonamiento jurídico e interpretación constitucional», ob cit., Pgs

${ }^{22}$ Atienza, Manuel, Las Razones del Derecho, Centro de Estudios Constitucionales, Madrid, $1991, \operatorname{Pg} 25$.

${ }^{23}$ Atienza, Manuel, Las Razones del Derecho, ob cit., pág. 46.

${ }^{24}$ Atienza, Manuel, «Para una Teoría de la Argumentación Jurídica», en Doxa, no 8, pág. 53 MacCormick, Neil, Legal Reasoning and Legal Theory, Clarendon Press, Oxford, 1978, pág. 65 y ss. Aarnio, Aulis, Lo Racional como Razonable, Centro de Estudios Constitucionales, Madrid, 1991, Pg 23-25. 
o existen dudas sobre qué norma hay que aplicar a un caso $\mathrm{x}$; o existen dudas respecto de la inclusión de un objeto (hecho) $\mathrm{x}$ en la clase definida por los supuestos previstos en una norma; b) Problemas fácticos: existen dudas acerca de si un hecho $\mathrm{x}$ ha tenido lugar.

Si dejamos aparte a los problemas fácticos, la cuestión se centra en el papel que desempeña la lógica en la solución de problemas de ambigüedad, vaguedad y pluralidad normativa. Antes de responder a este punto es importante remarcar algunos papeles que la lógica no desempeña:

(i) En caso de ambigüedad, la lógica no nos proporciona un criterio para identificar a la mejor (la más justa, la más correcta) de las interpretaciones posibles de un texto legal;

(ii) en caso de vaguedad, la lógica no nos proporciona un criterio de decisión respecto del alcance (extensión) de un concepto;

(iii) en caso de pluralidad normativa, la lógica no nos proporciona un criterio para decidir acerca de la norma aplicable.

La lógica sólo proporciona un criterio para controlar la validez de una inferencia. Por consiguiente, es compatible con la justificación externa tanto de casos fáciles como de casos difíciles. Por ejemplo, respecto a la justificación de las premisas de un argumento, Atienza afirma acertadamente que: ${ }^{25}$

«... cuando se justifica una determinada decisión $d$, hay que ofrecer razones particulares A, B, C, en favor de la misma, pero tales razones particulares no son suficientes; se necesita ademas un enunciado normativo general que indique que siempre que se den las circunstancias A, B, C, debe tomarse la decisión X.

El enunciado normativo general podría ser, por ejemplo, siguiendo a Aarnio: ${ }^{26}$

«En la decisión de un caso difícil se debe tratar de alcanzar una solución tal que la mayoría de los miembros racionalmente pensantes de la comunidad jurídica pueda aceptar esa solución y esa justificación».

$\mathrm{O}$, también podría ser, siguiendo a MacCormick, que el enunciado normativo general exija tener en cuenta, para la justificación de segundo orden, la consistencia, coherencia y consecuencias de la decisión ${ }^{27}$. O,

${ }^{25}$ Atienza. Manuel. Las Razones del Derecho, ob cit. pág. 141.

${ }^{26}$ Aarnio, Aulis. «Da tesis de la respuesta correcta y, el principio regulativo del razonamiento práctico» en Doxa, N8. pág. 37.

${ }^{27}$ MacCormick. Neil. Legal Reasoning and Legal Theory,, ob cit, Capítulo V. Por ejemplo, en «The artificial reason and judament of law», Recthstheorie, Beiheft 2. Berlín, 1981, pág. 109, 110. afirma: «Each side has to show that it seeks not some act of particular grace, but instead seeks what is right in the circunstances. But what is right in the circunstances is right for any such circunstances»». 
quizás como sugiere Dworkin al caracterizar al positivismo jurídico, que los jueces deben actuar como lo haría el mismo legislador si hubiera previsto el caso ${ }^{28}$.

Después de la elección de una premisa normativa general (PNG), es necesario analizar cuál de las distintas alternativas disponibles satisface a PNG, por ejemplo: cuál de las distintas interpretaciones de una formulación normativa satisface a PNG. Obviamente, la posibilidad de controlar esta decisión de un caso mediante las reglas del razonamiento deductivo surge a posteriori de la elección de las premisas: la lógica no señala qué premisas debemos escoger. Pero esto ocurre tanto en casos fáciles como en casos difíciles ${ }^{29}$. Por consiguiente, no hay razones para pensar que la justificación de las premisas en un caso difícil no puede ser controlada conforme a la lógica deductiva. Más aún, si es verdad que ${ }^{30}$ «la lógica que -como la gramática- es una disciplina prescriptiva: no dice cómo los hombres piensan o razonan de hecho, sino cómo deberían hacerlo»; entonces también es verdad que prescindir de la lógica en el control de la validez de las inferencias que establecen las premisas en un caso difícil, es comportarse como no deberíamos hacerlo. Obviamente, la lógica no asegura que diferentes sujetos utilicen los mismos enunciados generales para justificar las premisas de un argumento en un caso difícil. Pero, tampoco asegura que utilicen las mismas premisas en un caso fácil. En ambos casos (fáciles y difíciles) es necesario decidir acerca de las premisas a utilizar en la justificación. Y, como señala MacCormick, «decidir no es deducir ${ }^{31}$.

Es claro que si se admiten estas consideraciones, los argumentos deductivos se presentarán habitualmente en forma entimemática ${ }^{32}$. Pero, en este punto, la lógica también constituye una herramienta útil: si el argumento es entimemático, existe una premisa de ese argumento que no ha sido formulada y con la ayuda de la lógica podemos explicitarla, para someterla -si fuera necesario- a la discusión y al análisis crítico. En este sentido, al hacer explícita la premisa presupuesta no se añade ninguna premisa nueva al argumento, sino que se pone de manifiesto uno de los fundamentos de la conclusión.

${ }^{28}$ Dworkin, Ronald, Los derechos en erio, Ariel, Barcelona, 1984, pág. 147.

${ }^{29}$ Caracciolo, Ricardo, «Racionalidad Objetiva y Racionalidad Subjetiva», en Doxa, no 4, pág. 151.

${ }^{30}$ Atienza, Manuel, Las Razones del Derecho, ob cit, pág. 34.

${ }^{31}$ La cita la tomamos de Alchourrón, Carlos y Bulygin, Eugenio, «Los Limites de la Lógica y el Razonamiento Jurídico», ob cit, Pg. 303.

${ }^{32}$ Atienza, Manuel, Las Razones del Derecho, ob cit, pág. 41 y 42. 
3) Hay un punto importante que destacan correctamente quienes se ocupan de la justificación de las decisiones normativas: la premisa mayor de la inferencia no puede ser una proposición. Si la conclusión del argumento es una norma dictada por el órgano competente, entonces tiene que existir una norma que justifique el contenido de la decisión. Pero esto nos enfrenta a un problema diferente: si las normas no poseen valores veritativos, no pueden ser premisas ni conclusiones de una inferencia válida. Una argumentación es lógicamente válida cuando es imposible que sus premisas sean verdaderas y no lo sea su conclusión. Este criterio semántico de la validez de los argumentos conduce al bien conocido dilema de Jorgensen. Alchourrón y Bulygin lo formulan de la siguiente manera: ${ }^{33}$

«... O bien la noción de inferencia y las conectivas proposicionales son caracterizadas en términos de verdad y entonces no hay una lógica de normas y las conectivas lógicas no pueden operar sobre normas, o bien hay una lógica de normas, pero entonces el concepto de inferencia y las conectivas lógicas no pueden definirse en términos de la verdad».

Atienza se inclina por el segundo cuerno del dilema y afirma: ${ }^{34}$

«... los autores que sostienen la tesis de que la lógica no se aplica a las normas están, en realidad, confundiendo los términos del problema, en cuanto no parecen haber reparado en el diferente carácter que tienen estas dos preguntas. Por un lado está la cuestión de si la relación que guardan entre sí las normas válidas (en el sentido de pertenecientes a un sistema) son relaciones de tipo lógico. La respuesta a esta pregunta es obviamente negativa, puesto que es posible que a un mismo sistema pertenezcan normas contradictorias entre sí.»

La respuesta a la pregunta de Atienza, tendría que ser afirmativa: si dos normas se contradicen entre sí entonces hay, al menos, una relación lógica de contradicción normativa. Pero, esta conclusión presupone lo que se tiene que mostrar: que existen relaciones lógicas entre normas y, especialmente, contradicciones normativas.

Sin embargo, Atienza añade: ${ }^{35}$

«Y por otro lado está la cuestión de si se puede inferir válidamente una norma de otra. La respuesta a esta última pregunta es perfectamente independiente de la anterior, y no se ve por qué no ha de ser afirmativa.»

Pero, es claro que si se admite la existencia de contradicciones normativas, entonces es necesario admitir la relación de inferencia entre

${ }^{33}$ Alchourrón, Carlos y Bulygin, Eugenio, «Los limites de la lógica y el razonamiento jurídico» en Análisis Lógico y Derecho, ob cit., pág. 321.

${ }^{34}$ Atienza, Manuel, Las Razones del Derecho, ob cit., pág. 35.

${ }^{35}$ Atienza, Manuel, Las Razones del Derecho, ob cit., pág. 35 y 36. 
normas; ya que la afirmación de que una norma $\mathrm{N}$ y una norma $\mathrm{N} 1$ se contradicen implica al enunciado «la negación de N1 se infiere de N». Por consiguiente, los problemas no son independientes y en ambos Atienza presupone una respuesta afirmativa al problema de la aplicabilidad de la lógica al derecho. En este sentido añade: ${ }^{36}$

«En realidad, el problema con el que nos tropezamos aquí es que en la definición de argumento deductivo antes aceptada, se contemplaba únicamente enunciados susceptibles de ser calificados como verdaderos o falsos, y esta característica... no la poseen las normas.»

Para superar esta dificultad, Atienza propone la siguiente reformulación: ${ }^{37}$

Tenemos una implicación o una inferencia lógica o una argumentación válida (deductivamente), cuando la conclusión necesariamente es verdadera (o bien, correcta, justa, válida, etc.) si las premisas son verdaderas (o bien, correctas, justas, válidas, etc.)»

Esta redefinición del concepto de inferencia presupone que el concepto de verdad puede ser sustituido por otras propiedades posibles del discurso prescriptivo. Pero el problema es encontrar un criterio que relacione necesariamente a las premisas y la conclusión. En el caso de las proposiciones, el criterio de validez es que para cualquier valor de verdad asignado a las proposiciones, no hay una combinación veritativa que haga verdaderas las premisas y falsa a la conclusión. Pero, en el discurso prescriptivo, no existe una propiedad que sea similar a la verdad de una proposición y esta es la razón de que muchos filósofos abandonaran el intento de construir una lógica de normas ${ }^{38}$.

En resumen, hemos tratado de mostrar que la lógica no proporciona un argumento a favor de la relación necesaria entre derecho y moral. También hemos señalado que la resolución de casos difíciles no escapa, necesariamente, del ámbito del razonamiento deductivo.

Finalmente, es importante advertir que una clara concepción de la naturaleza del razonamiento (teórico, práctico, jurídico, etc.) implica y es implicada por una clara comprensión acerca de la naturaleza de la lógica. En este sentido, el análisis de las teorías contemporáneas de la argumentación jurídica y del razonamiento práctico poseen un innegable valor. Si, adicionalmente, se acuerda que el progreso en filosofía tiene directa relación con la reformulación y revisión de los interrogantes clásicos ${ }^{39}$, entonces hay que reconocer a estas teorías su genuina importancia.

\footnotetext{
${ }^{36}$ Atienza, Manuel, Las Razones del Derecho, ob cit., pág. 36.

${ }^{37}$ Atienza, Manuel, Las Razones del Derecho, ob cit, pág. 36.

${ }^{38}$ Von Wright, Georg, «Is and Ought», en Man, Law and Modern forms of Life, ob cit.

${ }^{39}$ Von Wright, Georg, «On Human freedom» en The Tanner Lectures on Human Values, Vol VI, University of Utah Press, 1985, pág. 109 y ss.
} 